\title{
Darf ich vorstellen: der neue Chefredaktor
}

\author{
Ludwig T. Heuss, Präsident des Verwaltungsrates EMH AG
}

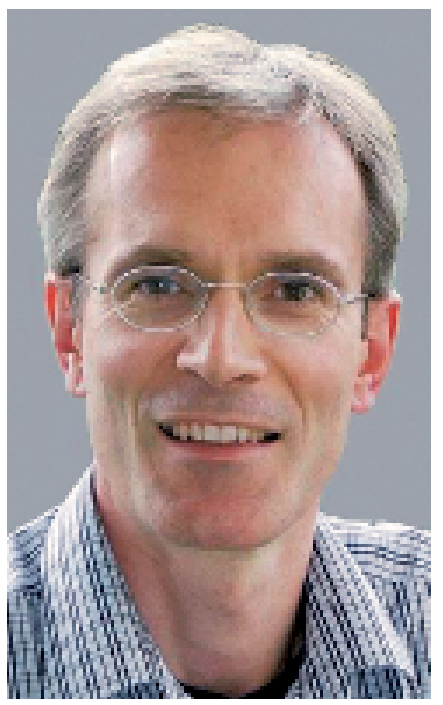

Bruno Kesseli
Das lange Warten hat ein Ende. Mit grosser Freude darf ich Ihnen heute den neuen Chefredaktor der Schweizerischen Ärztezeitung vorstellen: Bruno Kesseli hat am 1. November 2005 diese Aufgabe übernommen und führt seither das Flaggschiff des Schweizerischen Ärzteverlages EMH.

Das lange Warten hat sich auch gelohnt, denn Dr. med. et lic. phil. I Bruno Kesseli ist für diese Position eine Idealbesetzung. Der neue Chefredaktor ist Arzt, genauer Facharzt für Allgemeinmedizin FMH, und kennt damit die ärztliche Tätigkeit nicht nur theoretisch, sondern auch praktisch. Der neue Chefredaktor ist aber auch Journalist, mit abgeschlossenem Studium der Germanistik, Geschichte und Publizistikwissenschaften, ein Journalist aber auch, der das Handwerk des Schreibens beherrscht. Während vier Jahren leitete er das Kulturressort einer regionalen Wochenzeitung. Daneben zeugt eine Viel- zahl von Publikationen in überregionalen Tageszeitungen, unter anderem Tages-Anzeiger und NZZ, von einem breiten journalistischen Schaffen, das sich von Innenpolitik über Kultur bis zum Sport erstreckte. Selbstredend, dass sich in den vergangenen Jahren sein journalistischer Fokus auf medizinjournalistische Tätigkeiten und Gesundheitspolitik ausrichtete.

Kurzum: Der neue Chefredaktor, 43jährig, verheiratet und Vater von drei Kindern, ist für diese Stelle geschaffen. Er kennt Materie und Handwerk à fond. Wir freuen uns, dass wir Bruno Kesseli für diese Aufgabe gewinnen konnten, und sind sicher, dass er die Schweizerische Ärztezeitung profilieren und weiterentwickeln wird. Die redaktionelle Freiheit hierzu ist ihm zugesichert.

Ich freue mich sehr auf die Zusammenarbeit und wünsche Bruno Kesseli einen guten Start!

\section{Présentation du nouveau rédacteur en chef}

\author{
Ludwig T. Heuss, président du Conseil d'administration des éditions EMH SA
}

Après une longue attente, c'est avec joie que je vous présente aujourd'hui le nouveau rédacteur en chef du Bulletin des médecins suisses: Bruno Kesseli est entré en fonction le $1^{\text {er }}$ novembre 2005. Il mènera dès lors la barque des Editions médicales suisses (EMH)

L'attente en a valu la peine, puisque Bruno Kesseli, docteur en médecine et licencié en lettres, remplit les conditions idéales pour ce poste. Le nouveau rédacteur en chef est en effet médecin, plus précisément spécialiste en médecine générale FMH. Ses connaissances médicales ne sont pas que théoriques, mais pratiques. Mais le nouveau rédacteur en chef n'en est pas resté là. Il est aussi journaliste, après des études brillantes en germanistique, histoire et journalisme: la maîtrise de l'écriture n'est pour lui pas un vain mot.

Il dirigea pendant quatre ans la partie culturelle d'un hebdomadaire régional et peut se targuer d'un grand nombre de publications dans des quotidiens suisses, notamment dans le TagesAnzeiger et la NZZ, ce qui lui confère une large culture journalistique, de la politique intérieure au sport, en passant par la culture. Il semble aller de soi que son intérêt d'homme de plume se soit porté ces dernières années sur les volets médicaux de son activité, ainsi que sur la politique de santé.

En bref, je dirai encore que le nouveau rédacteur en chef, 43 ans, marié et père de trois enfants, est fait pour le «job». Il connaît la matière à fond, au propre comme au figuré. Nous sommes heureux de nous adjoindre ses services et convaincus qu'il saura peaufiner le profil du Bulletin des médecins suisses et le développer. Une pleine liberté rédactionnelle lui est assurée.

Je me réjouis de cette nouvelle collaboration et souhaite à Bruno Kesseli un bon départ! 